\title{
BMJ Open Incentives and disincentives for treating of depression and anxiety in Ontario Family Health Teams: protocol for a grounded theory study
}

\author{
Rachelle Ashcroft, ${ }^{1}$ Matthew Menear, ${ }^{2,3}$ Jose Silveira, ${ }^{4,5}$ Simone Dahrouge, ${ }^{6}$ \\ Kwame McKenzie ${ }^{5,7,8}$
}

To cite: Ashcroft $\mathrm{R}$, Menear M, Silveira J, et al. Incentives and disincentives for treating of depression and anxiety in Ontario Family Health Teams: protocol for a grounded theory study. BMJ Open 2016;6:e014623. doi:10.1136/bmjopen-2016014623

- Prepublication history for this paper is available online. To view these files please visit the journal online (http://dx.doi.org/10.1136/ bmjopen-2016-014623).

Received 10 October 2016 Accepted 19 October 2016

CrossMark

For numbered affiliations see end of article.

Correspondence to Dr Rachelle Ashcroft; rachelle.ashcroft@utoronto.ca

\section{ABSTRACT}

Introduction: There is strong consensus that prevention and management of common mental disorders (CMDs) should occur in primary care and evidence suggests that treatment of CMDs in these settings can be effective. New interprofessional teambased models of primary care have emerged that are intended to address problems of quality and access to mental health services, yet many people continue to struggle to access care for CMDs in these settings. Insufficient attention directed towards the incentives and disincentives that influence care for CMDs in primary care, and especially in interprofessional teambased settings, may have resulted in missed opportunities to improve care quality and control healthcare costs. Our research is driven by the hypothesis that a stronger understanding of the full range of incentives and disincentives at play and their relationships with performance and other contextual factors will help stakeholders identify the critical levers of change needed to enhance prevention and management of CMDs in interprofessional primary care contexts. Participant recruitment began in May 2016.

Methods and analysis: An explanatory qualitative design, based on a constructivist grounded theory methodology, will be used. Our study will be conducted in the Canadian province of Ontario, a province that features a widely implemented interprofessional team-based model of primary care. Semistructured interviews will be conducted with a diverse range of healthcare professionals and stakeholders that can help us understand how various incentives and disincentives influence the provision of evidence-based collaborative care for CMDs. A final sample size of 100 is anticipated. The protocol was peer reviewed by experts who were nominated by the funding organisation.

Ethics and dissemination: The model we generate will shed light on the incentives and disincentives that are and should be in place to support high-quality CMD care and help stimulate more targeted, coordinated stakeholder responses to improving primary mental healthcare quality.

\section{Strengths and limitations of this study}

- This study will provide new information on incentives and disincentives that influence the provision of mental healthcare for common mental disorders (CMDs) in a collaborative primary care setting.

- Protocol carefully constructed in a way to help develop an explanatory model which will help policy and decision makers strengthen care for CMDs.

- A limitation of this study is that it is based in one geographical region (Ontario, Canada) and therefore is not representative of all primary care models and contexts.

\section{INTRODUCTION}

Common mental disorders (CMDs) such as depression and anxiety disorders are highly prevalent, affecting more than one in five Canadians over their lifetime. ${ }^{12}$ These disorders cause considerable suffering and impart a significant burden on affected individuals, their families and all of society. ${ }^{1}{ }^{2}$ For example, CMDs increase the risk of workplace absenteeism and productivity thus lowering one's income and increasing risk of unemployment. ${ }^{12}$ Major depression has a lifetime prevalence of $11 \%$ and an annual prevalence of $5 \% .{ }^{13}$ Lifetime prevalence of all anxiety disorders combined is reportedly as high as $31 \%,{ }^{4}$ with annual prevalence rates ranging from $12 \%$ to $18 \%{ }^{4}$ These CMDs are a leading cause of disability worldwide $^{5}$ and can lead to significant distress and loss of daily functioning. ${ }^{14}$ CMDs also have a substantial impact on society, being associated with greater healthcare service use and decreased workforce productivity. ${ }^{1}{ }^{4}$ There is consensus that the best way to respond to the population need for 
prevention and management of CMDs is to increase capacity for mental healthcare in primary care. ${ }^{6}{ }^{7}$ CMDs are commonly encountered in primary care, with primary care considered the ideal location for the prevention and management of CMDs, for several reasons. ${ }^{8} 9$ Primary mental healthcare services are person-centred and comprehensive, providing an optimal communitybased setting for early identification, treatment, education and counselling, and prevention of recurrence. ${ }^{710}$ Care can be best coordinated at this level, where primary care providers can help patients navigate different parts of the healthcare system. ${ }^{6}$ Patients can also build long-term relationships with their family physicians, allowing these professionals to develop unique insights that assist diagnosis and treatment. ${ }^{11}$ With recent reforms, access to interprofessional primary care teams has the potential to offer holistic management of mental and physical health problems. ${ }^{11} 12$

Several systematic reviews suggest that treatment of CMDs in primary care can be effective. ${ }^{13-15}$ Two recent high-quality meta-analyses showed for instance that antidepressants ${ }^{13}$ and psychological treatments ${ }^{14}$ are both effective and acceptable treatments for depression in primary care. Integrating treatment of CMDs into primary care is associated with better patient outcomes than non-integrated care, including improved treatment response, remission rates, quality of life and satisfaction with treatment. ${ }^{16}$ Treating CMDs in primary care improves overall healthcare system performance and efficiency and lowers total healthcare costs. ${ }^{16} 17$

\section{Care gaps for CMDs in primary care}

Though there is strong national and international support for delivering mental health services in primary care, many people suffering from CMDs fail to receive timely, appropriate care in these settings. Canadian studies reveal that $90 \%$ of people living with CMDs will visit their family physician during the year ${ }^{18} 19$ but only a small fraction of these patients will consult for mental health reasons. ${ }^{18}{ }^{20}$ More than $40 \%$ of people living with CMDs receive no mental healthcare whatsoever, ${ }^{21-23}$ while more than $30 \%$ of patients receiving care for CMDs in primary care report unmet needs for care. ${ }^{24}$ Patients with mental health conditions report lower access to primary care services (eg, access both during and outside regular hours, availability of same-day appointments)..$^{25}$

CMDs are frequently under-recognised and ineffectively managed in primary care. For example, only $50 \%$ of individuals with CMDs are identified. ${ }^{26-28}$ Research has shown that patients often live with CMDs and go untreated for years before their illness is finally detected and managed. ${ }^{29}{ }^{30}$ Even after being recognised, patients with CMDs often do not receive appropriate or adequate care. A systematic review by Duhoux $e t a l^{31}$ on the quality of care for depression in primary care found rates of minimally adequate treatment (ie, receiving either minimal guideline-consistent pharmacotherapy or psychotherapy) ranging from $14 \%$ to $56 \%$ across studies. Similar findings of inadequate treatment quality have been observed for anxiety disorders, as more than half of treated patients either fail to receive an appropriate dose or duration of pharmacological treatment or receive psychotherapy inconsistent with evidence-based practices. ${ }^{32}{ }^{33}$ Studies investigating the care for CMDs in primary care settings in Ontario have reported similar problems with under-recognition and inadequate treatment of these disorders. ${ }^{20-34}$

\section{Primary health care reforms in Canada}

In the early 2000s, provincial and territorial governments across Canada introduced several reforms aimed at strengthening primary care systems by improving access to care, quality of care, and the coordination and integration of services. ${ }^{35} 36$ In Ontario, reform trends included a shift away from fee-for-service-based physician remuneration to a capitation-based system, patient enrolment to individual physicians, and the expansion of interprofessional team-based practices, primarily through the creation of Family Health Teams (FHTs). ${ }^{35} 36$

Transitioning from the traditional fee-for-service model to a reform model was entirely voluntary. However, attribution of the resources to establish an interprofessional model of care was competitively based and required that practices establish a business case demonstrating how their interprofessional structure would support better care delivery to their practice population. Since their introduction in 2005, 184 FHTs were funded and operationalised over five waves of implementation with the final 50 implemented in 2011/ 2012. ${ }^{37}$ Currently, FHTs serve 2.9 million Ontarians, or $21.5 \%$ of the population. ${ }^{38-40}$ FHT composition varies by region but typically comprises family physicians, nurses, nurse practitioners, and often includes pharmacists, dieticians, social workers and other professionals (eg, occupational therapists, psychologists). ${ }^{41}$ FHTs are intended to be a flexible model shaped by community needs and so there is considerable variation between them in terms of size, provider composition and types of services that are offered. ${ }^{35-38} 41$

Though they are not the only primary care model in Ontario, FHTs have been the focus of considerable recent investment in the province. ${ }^{36} 38$ The FHT model closely resembles other team-based care and 'medical home' models of care that are expanding across Canada and the USA. ${ }^{40}$ Ontario's mental health action plan also underscores the FHTs' potential in improving mental healthcare through collaborative action. ${ }^{42}$

\section{Primary mental health care reforms and challenges}

Alongside these recent efforts to reform primary care services have been attempts to strengthen the delivery of mental health services within primary care ${ }^{43}$ notably by promoting the delivery of more collaborative mental healthcare practices. ${ }^{6}{ }^{43}$ The literature identifies several 
components of collaborative care programmes: (1) a care manager that supports patient education and selfmanagement and contributes to care coordination, (2) primary care provider access to psychiatric consultation and advice, (3) early identification or screening processes and proactive, structured patient follow-up, (4) delivery of evidence-based pharmacological and psychological treatments, and (5) enhanced interprofessional communication (eg, through team meetings, shared medical records). ${ }^{64-46}$ Collaborative care interventions featuring these components are highly effective in improving outcomes for primary care patients with major depression or anxiety disorders. ${ }^{64-48}$

However, integrating mental healthcare within primary care remains a longstanding challenge in Canada. ${ }^{17}$ In Ontario, numerous barriers to integration have been encountered: inconsistent collaboration between family physicians and mental health professionals; poor access to psychiatric consultations; limited time dedicated to mental health preventive care; challenges with hiring mental health professionals-particularly in rural areas; and disconnects between FHTs and other communitybased mental health providers. ${ }^{11} 17{ }^{49-51}$ Furthermore, the funding models intended to incentivise physicians have been recognised as a challenge for integrating physical and mental healthcare in FHTs. ${ }^{17}$

\section{Incentives and disincentives-leveraging change}

Incentives constitute key tools in the design of healthcare systems to leverage individual provider and organisational change. ${ }^{52-55}$ Informed by behaviour theory, ${ }^{53}$ an incentive refers to a catalyst that encourages healthcare professionals, healthcare teams and organisations to take a particular action. ${ }^{56}$ Good incentive designs help align behaviour of individual providers or organisations with overarching health policy objectives. ${ }^{53-57}$

Yip et $a \bar{l}^{2}$ provide a conceptual model illustrating a range of external and internal incentives that may motivate an individual provider or organisation to achieve intended health policy outcomes. For example, external incentives that may motivate individual providers and organisations include financial incentives, norms, changes to reputation and regulations. Examples of internal motivating incentives are professional ethics, altruism and the desire to protect patient welfare. Despite the existence of a broad range of non-financial incentives to leverage, financial incentives dominate the incentive literature. ${ }^{52} 535859$

Use of financial incentives to influence individual physician practice patterns is widespread. ${ }^{60}$ Financial incentives can include salary or sessional payments (payment for working a specific time period), fee-for-service payments (payment for each service or visit), capitation payments (payment for providing care for a patient or population), target payments and bonuses (payment to change or maintain specific behaviours), and blended approaches. ${ }^{61}$ Such financial incentives have been integral components of healthcare reforms worldwide, including reforms to primary care systems in the UK, USA, Australia and Canada. ${ }^{61-63}$ Major initiatives have revolved around pay-for-performance schemes, which provide explicit financial incentives in return for achieving certain quality targets. ${ }^{62}{ }^{63} \mathrm{~A}$ number of reviews suggest that effects of such financial incentives and pay-for-performance schemes are inconsistent. ${ }^{61-67}$ Overviews of reviews indicate that financial incentives seem to have little-to-modest impact on care processes and quality and inconclusive effects on patient outcomes and costs. $^{61}{ }^{68}$ Similarly, systematic reviews of pay-for-performance schemes suggest some positive but not sustained impacts on care quality and potential for negative unintended consequences for patient-centred care $^{65-67} \mathrm{~A}$ frequent concern among authors is that countries have introduced complex incentive schemes without a clear understanding of how they should be designed and how they might be mediated by other patient, provider, organisational or system-level factors. ${ }^{62} 6769$ This is problematic as evidence suggests that financial incentives are most consistently effective when design choices and contextual factors are optimised and aligned. ${ }^{62} 63 \quad 69$ When incentives schemes are inappropriately designed for their context, it can create disincentives for providers to provide certain types of care and lead to rapid cost increases, inefficiencies, deficits in care quality and erosion of medical ethics. ${ }^{52} 7071$

There is much uncertainty as to whether current incentive schemes support collaborative healthcare practices or whether they create disincentives to collaboration. ${ }^{36} 5972$ Design of healthcare systems must consider both incentives and disincentives to ensure that health system goals are achieved. ${ }^{73}$ Disincentive refers to a noxious stimulus that intentionally or unintentionally discourages individuals and organisations from acting in a certain way (ie, a deterrent). ${ }^{53} 5658$ Disincentives can arise from problems in design or implementation of particular incentive schemes. ${ }^{52} 71$ Identification and elimination of disincentives resulting in individual or organisational behaviour running contrary to goals of providing high-quality, cost-efficient care is necessary to achieve policy objectives in primary care. ${ }^{56} 74$

Relatively little is known about the financial and other incentives and disincentives that influence the provision of mental healthcare in primary care settings. ${ }^{56}{ }^{75}$ Authors have argued that financial incentives may influence whether mental healthcare is considered a core service, an add-on service, or even ignored, how mental healthcare services are configured, who is included as a service provider, and whether or not psychiatry is involved or even referred to. ${ }^{76}$ Financial incentives may also impact on the content of care and affect the provision of prevention, screening, treatment, follow-up and even collaborative care approaches to care. ${ }^{50} 76-79$ While most attention has been paid towards financial incentives, it is recognised that health professionals are only partially motivated by such incentives. ${ }^{53} 80$ Non-financial incentives and disincentives are also 
thought to influence the content of mental healthcare. For instance, limited knowledge and not having screening tools appropriate for primary care may discourage early detection of CMDs. ${ }^{81}{ }^{82}$ Time restrictions in the scheduling of patient appointments may act as a deterrent for screening. ${ }^{82}{ }^{83}$ Psychological treatments may be restricted because of a lack of appropriate healthcare providers, allocated time or organisational space. ${ }^{84}{ }^{85} \mathrm{In}$ a recent scoping review, we identified six different types of incentives and disincentives that can shape the provision of primary mental healthcare for CMDs: (1) attitudes and beliefs, (2) training and core competencies, (3) leadership, (4) organisational incentives, (5) financial incentives and (6) systemic incentives. ${ }^{74}$

Since 2000, Ontario has pursued new physician reimbursement models. ${ }^{36}$ A core component of the FHT model is an innovative financial incentive structure. ${ }^{39} 86$ Physicians practicing in FHTs are reimbursed through various blends of payment types with capitationpayment per patient per month-being a key reimbursement model. ${ }^{36}$ The various funding sources that comprise the FHT funding model include physician payments, bonuses for specific care activities identified by the Ministry of Health and Long Term Care (MOHLTC), funding for interdisciplinary provider salaries, and any additional sources of Ontario government funding that may be provided directly to FHTs. Financial incentives are important to the integration of mental health and primary care, ${ }^{76}$ yet it is currently unclear whether these incentives are supporting effective interprofessional care for CMDs by FHTs. When incentive structures are not aligned with other forms of incentives or fail to account for contextual factors such as organisational structures or stakeholder values, significant disincentives to the integration of mental health in primary care can be created. ${ }^{77}$ Preliminary evidence suggests that the incentives underpinning the FHT model may indeed be misaligned and acting as a barrier to achieving quality care for CMDs, ${ }^{49} 5674$ although we currently lack a comprehensive understanding of the full range of incentives and disincentives involved and how they may interact with each other to influence care.

\section{Objectives}

The objectives of this study are to: (1) identify the broad range of financial and non-financial incentives/disincentives that influence the prevention and management of CMDs by interprofessional primary care teams across Ontario, (2) construct a theoretical model that explains how incentives/disincentives operating at different levels of the healthcare system may be linked and how these are associated with collaborative mental healthcare practices and ultimately the quality of care for CMDs, and (3) incorporate in the theoretical model how stakeholder values and other organisational or contextual factors may mediate the effects of these incentives. We expect this work to advance understanding of how different levers of change can be used by different stakeholders (eg, primary care and mental health providers, team managers, provincial policymakers) to strengthen the prevention and management of CMDs in these teams in the future.

\section{METHODS AND ANALYSIS}

We will apply a constructivist grounded theory method, an approach where knowledge is viewed as socially constructed and stresses research that recognises multiple viewpoints, social contexts and interpretive understandings. ${ }^{87}$ It acknowledges that the subjectivity of researchers themselves and their biases and assumptions help shape the data collection and analysis and ultimately the theory that is generated. ${ }^{87}$ In the context of this study, our research team has specialisation in different disciplinary fields, including social work, psychiatry, population health, family medicine and the organisation of health services. We are an interdisciplinary team and our approach encourages integration of different viewpoints. ${ }^{87} 88$ A grounded theory approach was also considered appropriate, given our goal to develop a theoretical model that is firmly rooted in the perspectives of individuals with direct experience and knowledge of how various incentives and disincentives impact the quality of care for CMDs in interprofessional primary care teams. This study will run from June 2016 to May 2018 and is currently in the recruitment phase.

\section{Sample}

The 184 MOHLTC-funded FHTs represent the sampling frame for this study. We will purposively sample FHTs using a maximum variation sampling approach with respect to rurality of the urban $(\geq 10000$ inhabitants) or rural $(<10000$ inhabitants $)$ team size and composition. FHTs with a diverse range of established mental health services and programmes will be included. FHTs without any existing mental health services in the form of explicit mental health programmes and/or mental health professionals will also be included. Additional criteria for ensuring diversity will be considered as the study progresses based on emerging themes, as well as ensuring that a diverse range of healthcare professional types are included. There will be two phases of sampling for individual participants: initial and theoretical sampling.

\section{Initial sampling}

Initial sampling is recommended to help develop initial categories in the early phases of a study. ${ }^{87}$ Multiple perspectives both within and outside of FHTs will help gain an understanding of the wide range of incentives and disincentives that are perceived to influence care for CMDs in interprofessional primary care teams. Our initial sampling targets are FHT executive directors, FHT family physicians, FHT nurse practitioners, FHT mental health professionals, mental health providers outside of FHTs and provincial decision makers. 
Family physicians are a core healthcare professional across all FHTs. For someone to access the range of FHT services, including mental healthcare, most FHTs require that the physician will first have accepted the person onto his or her patient roster. Thus, inclusion of FHT physicians in this study is integral. Executive directors will be included in this study because they are often acutely aware of the different financial and other incentives and disincentives acting on team members and they will also provide valuable information about how FHT organisational structures may mediate these incentives. Nurse practitioners are important because within FHTs they can provide direct mental healthcare and also act as a liaison between the family physician and other mental health professionals within the FHT. ${ }^{89}$

Social workers and psychologists are important treatment providers in collaborative mental healthcare and yet little is known about their perceptions of the incentives and disincentives affecting the care they provide to people with CMDs. There is also some evidence that FHTs sometimes struggle to find their 'niche' with respect to mental health services when surrounded by other established mental health service providers in their communities. ${ }^{50}$ As such, gathering the views of these providers and of psychiatrists asked to play collaborative roles with primary care providers is critical. Finally, gaining a 'systems perspective' from policymakers and other provincial decision makers is essential to gain indepth understanding of the goals of these stakeholders for mental healthcare and the influence of various primary care system-level incentives (eg, financial, regulations, norms) on FHT team performance.

\section{Theoretical sampling}

Theoretical sampling will begin once we have some preliminary categories developed from our data, ${ }^{87}$ and when all members of the research team agree with pursuing theoretical sampling. In this phase of sampling, we will seek out the perspectives of all those participants that are needed to help us fully understand the relationships between incentives and disincentives, collaborative mental health practices in FHTs, and the quality of care for depressive and anxiety disorders. This will likely involve more interviews with the same types of stakeholders identified during the initial sampling phase, but possibly new stakeholders whose views are deemed important to gather. This sampling approach will also take us to new FHT settings that may further illuminate and add robustness to our model.

In this phase, the questions we pose to our participants will likely change. We have developed an interview guide for the initial sampling phase drawing on sensitising concepts emerging from our scoping literature review and pilot data. As we progress to theoretical sampling, the interview guide will likely be modified to reflect what emerges in the data. ${ }^{87}$ For example, if an incentive category emerges in the data and is not reflected on the initial interview guide, then as a research team, we may decide to add a question or probe that addresses the emerging category. Theoretical sampling thus helps fill out properties of a category and will facilitate development of an explanatory model about the incentives and disincentives influencing quality treatment for CMDs in FHTs.

\section{Data collection}

Data sources will include participant interviews and documents analyses. We will conduct face-to-face semistructured interviews with participants at their place of work or another location of their choosing. Interviews will last 60-90 minutes long and be conducted in French or in English, based on the participant's preference. With consent of individual participants, all interviews will be audio-recorded data and will be transcribed from audio-recorded data into text.

Documents collected for this study will either be provided voluntarily by participants or retrieved through targeted searches of online sources, such as the MOHLTC website or FHT websites. Examples of documents include government policy documents and guidance documents for FHTs, FHT organisational documents and written descriptions of services, or other documents relevant to incentives and disincentives for mental healthcare, collaborative care practices or the quality of care for CMDs.

\section{Recruitment and sample size}

FHTs will be placed into groups based on sampling criteria and an initial diverse set of FHTs will be contacted by email and/or phone by the first author. Contact information for FHTs is available publicly. An information package including an invitation to participate will be sent to FHTs by email requesting that it be disseminated by the executive director, lead physician, or another key resource person to other healthcare professionals working within the FHT. One key resource person per FHT will facilitate contact with the other members of the FHT who are most likely to be able to contribute to advancing the objectives of the study. These key resource people will also help us identify other potentially important community stakeholders outside of the FHT. Members of our advisory committee (described below) will also facilitate contacts with stakeholders outside of FHTs, especially provincial decision makers and policymakers. Prior to interviews, the first author or her research coordinator will contact all participants by email or phone and inform them of study objectives and procedures. The research coordinator will ensure a close follow-up of invitations sent to study participants.

When using grounded theory, data collection stops when theoretical saturation is reached, that is, the point in which data collection reveals no new properties or insights into the emerging theoretical model. ${ }^{87}$ In some studies, saturation can occur with as little as 10-12 interviews. $^{87}$ However, grounded theorists recommend 
increasing the number of interviews when constructing more complex conceptual analyses and theory development is being performed. ${ }^{87}$ We anticipate that engaging in a conceptual analysis on the topic of incentives and disincentives for CMD care in FHTs will be complex because of varying factors, including the number of stakeholders whose perspectives are important to include, the variation between FHTs in different geographic locations, the range of incentives and disincentives we are interested in and their relationships with other contextual factors, etc.

We thus estimate conducting a total of 100 interviews. We expect our initial sampling phase to involve $\sim 50$ interviews, which include interviews with each of the six groups of stakeholders we have identified. Initial sampling will target eight FHTs (four urban and four rural) and within each FHT we will seek the participation of the executive director, 1-2 family physicians and 2-3 other professionals (eg, nurse practitioners, social workers, psychologists). We will also invite one mental health provider in the area surrounding each of the eight FHTs to participate, as well as two provincial decision makers. We do not expect this data collection to result in theoretical saturation and so interviews involving 6-8 new FHTs and new participants will continue until saturation is reached. If relevant, select participants will be reinterviewed to gather additional data informing our theoretical model. We thus expect this theoretical sampling phase to require another 50 interviews, an estimate informed by other rigorous grounded theory studies. ${ }^{90} 91$

\section{Data analysis}

Our analysis will be conducted in an iterative way where data collection and data analysis will occur simultaneously. ${ }^{87}{ }^{92}$ Interviews will be transcribed soon after taking place (optimally within 2 weeks of the interview) and the first analysis step will involve line-by-line open coding of interviews and documents to tie concepts to blocks of raw data. ${ }^{87}$ Sensitising concepts identified in our scoping review and pilot data will help the initial process of coding data. Sensitising concepts provide starting points for initiating analysis but do not determine the content. ${ }^{87}$ Two research team members will participate in the coding process and will regularly share findings and reflections with the rest of the research team.

Focused coding is the second phase of coding. Focused coding refers to those codes that appear more frequently during the initial coding phase, or have more significance than other codes. Our approach to the third phase of coding-traditionally referred to as axial coding-will be inspired by Charmaz. ${ }^{87}$ The purpose of the third phase of coding is to develop subcategories for categories and show the links between them. Emergent analytic strategies will be used to determine how the categories connect together. Theoretical coding is the fourth phase of coding that follows codes selected during focused coding. Theoretical coding establishes how substantive codes relate to each other and integrate into theory. ${ }^{87}$ The latter two phases of coding are especially important in the development of our theoretical model and will be done as a research team. It is likely that we will be able to construct models representing the perspectives of several stakeholder groups involved in the study, which can then be merged into a final comprehensive model illustrating relationships between incentives and disincentives, contextual factors, collaborative or interprofessional practices and performance concepts such as quality of care. The electronic data management programme NVivo will be used to help organise the data analysis process and generate initial figures representing the data.

\section{Validity}

Four factors will contribute to validity or 'trustworthiness' of findings. ${ }^{93}$ First, a rigorous audit trail will be kept for all aspects of the study and design. Second, the research team will engage in regular internal debriefing to facilitate a check of the research process. ${ }^{93}$ Third, having different healthcare providers and stakeholders in the sample and including document analysis promotes triangulation of multiple sources of data. Finally, we will engage in member checking in two ways. The first approach will be to present our findings to members of our advisory committee, which will be composed of eight individuals representing different stakeholder groups relevant to our study. A second approach will be to gather feedback from participants at two stages in the model generation process: after initial sampling once an initial model has been constructed and after theoretical sampling when a final model is being constructed. We will coordinate member checking with the help of the key resource people from each of the FHTs involved in the study.

\section{ETHICS AND DISSEMINATION}

Participants will be given information about the project orally as well as in a written informed consent. Publications and presentations will present findings anonymously. Excerpts and quotations will be anonymised using a randomly assigned participant code. Research Ethics Board Approval has been granted by the University of Toronto, Centre for Addictions and Mental Health, Bruyère Research Institute, St. Joseph's Health Centre (Toronto), and Laval University.

There are four knowledge transfer (KT) goals of this research project; namely, (1) increase knowledge and awareness of the disincentives that are deterring mental healthcare in FHTs, (2) increase knowledge and awareness of the incentives that can assist to increase mental healthcare in FHTs, (3) inform policy change to help facilitate greater inclusion of mental healthcare in FHTs, and (4) inform future research. The KT strategy will concentrate efforts on audiences in Ontario and 
Canada. Findings will be presented at relevant conferences. Findings will also be published in peer-reviewed journals and plain language summary reports will be disseminated.

In addition, an advisory committee consisting of stakeholders and decision makers to whom the study results will be particularly relevant was established at the onset of the study. We expect to have the advisory committee remain active for the entire 3-year duration of the research study. The advisory committee is expected to provide feedback on the research process, help interpret results, develop recommendations and disseminate study findings. Additional end-of-grant KT activities will be determined in consultation with the advisory committee.

\section{CONCLUSION}

Findings from this study aim to help policymakers in strengthening of treatment for CMDs in Ontario FHTs. Our model will demonstrate how non-financial and financial incentives can help leverage improvement for prevention and management of CMDs, and mitigate effects of disincentives currently deterring quality care. The bulk of literature on primary care incentives focuses on single-provider models of care. This research is unique because it will help to generate knowledge about incentive models relevant for interprofessional primary care settings. The knowledge gained from this study and its main output (our model) will be an important stepping stone to improve the prevention and management of CMDs in interprofessional primary care settings in Ontario and other jurisdictions.

\author{
Author affiliations \\ ${ }^{1}$ Factor-Inwentash Faculty of Social Work, University of Toronto, Toronto, \\ Ontario, Canada \\ ${ }^{2} \mathrm{CHU}$ de Quebec Research Centre, Quebec City, Quebec, Canada \\ ${ }^{3}$ Department of Family Medicine and Emergency Medicine, Laval University, \\ Quebec City, Quebec, Canada \\ ${ }^{4}$ Mental Health and Addiction Program, St. Joseph's Health Centre, Toronto, \\ Ontario, Canada \\ ${ }^{5}$ Department of Psychiatry, University of Toronto, Toronto, Ontario, Canada \\ ${ }^{6}$ C.T. Lamont Primary Health Care Research Centre, Bruyere Research \\ Institute, Ottawa, Ontario, Canada \\ ${ }^{7}$ Wellesley Institute, Toronto, Ontario, Canada \\ ${ }^{8}$ Centre for Addiction and Mental Health, Toronto, Ontario, Canada
}

Contributors RA, MM, JS, SD, KM conceptualised and designed the study. RA and MM drafted the manuscript. MM, SD, JS, KM critically revised the manuscript. RA took the lead and compiled critical revisions. RA and MM edited each draft version. RA, MM, SD, JS, KM approved the final manuscript and agree to be accountable for all aspects of the work.

Funding This research is supported by the Canadian Institutes of Health Research (CIHR funding referencing number: MOP-142435) PI: Ashcroft, R, (Operating Funds: \$295 419; 2015-2018).

Competing interests None declared.

Ethics approval University of Toronto.

Provenance and peer review Not commissioned; peer reviewed for ethical and funding approval prior to submission.

Open Access This is an Open Access article distributed in accordance with the Creative Commons Attribution Non Commercial (CC BY-NC 4.0) license, which permits others to distribute, remix, adapt, build upon this work noncommercially, and license their derivative works on different terms, provided the original work is properly cited and the use is non-commercial. See: http:// creativecommons.org/licenses/by-nc/4.0/

\section{REFERENCES}

1. Patten SB, Kennedy SH, Lam RW, et al. Canadian Network for Mood and Anxiety Treatments (CANMAT) clinical guidelines for the management of major depressive disorder in adults. I. Classification, burden and principles of management. J Affect Disord 2009;117 (Suppl 1):S5-14.

2. Lépine JP, Briley M. The increasing burden of depression. Neuropsychiatr Dis Treat 2011;7(Suppl 1):3-7.

3. Pearson C, Janz T, Ali J. Mental and substance use disorders in Canada. Health at a Glance. Statistics Canada, 2013(82-624-X):1-8

4. Katzman MA, Bleau $\mathrm{P}$, Blier $\mathrm{P}$, et al. Canadian clinical practice guidelines for the management of anxiety, posttraumatic stress and obsessive-compulsive disorders. BMC Psychiatry 2014;14(Suppl 1): S1.

5. Whiteford HA, Degenhardt L, Rehm J, et al. Global burden of disease attributable to mental and substance use disorders: findings from the Global Burden of Disease Study 2010. Lancet 2013;382:1575-86.

6. Kates N, Mazowita G, Lemire F, et al. The evolution of collaborative mental health care in Canada: a shared vision for the future. CJP 2011;56:1-10.

7. World Health Organization and World Organization of Family Doctors (Wonca). Integrating mental health into primary care: a global perspective. Geneva, World Health Organization: 2008.

8. Serrano-Blanco A, Palao DJ, Luciano JV, et al. Prevalence of mental disorders in primary care: results from the diagnosis and treatment of mental disorders in primary care study (DASMAP). Soc Psychiatry Psychiatr Epidemiol 2010;45:201-10.

9. Waraich P, Goldner EM, Somers JM, et al. Prevalence and incidence studies of mood disorders: a systematic review of the literature. Can J Psychiatry 2004;49:124-38.

10. American Academy of Child and Adolescent Psychiatry. Improving mental health services in primary care: reducing administrative and financial barriers to access and collaboration. Pediatrics 2009;123:1248-51.

11. Rush B, McPherson-Doe C, Behrooz RC, et al. Exploring core competencies for mental health and addictions work within a Family Health Team setting. Ment Health Fam Med 2013;10:89-100.

12. Gilbody S, Bower P, Fletcher J, et al. Collaborative care for depression: a cumulative meta-analysis and review of longer-term outcomes. Arch Intern Med 2006;166:2314-21.

13. Linde K, Kriston L, Rücker G, et al. Efficacy and acceptability of pharmacological treatments for depressive disorders in primary care: systematic review and network meta-analysis. Ann Fam Med 2015;13:69-79.

14. Linde K, Sigterman K, Kriston L, et al. Effectiveness of psychological treatments for depressive disorders in primary care: systematic review and meta-analysis. Ann Fam Med 2015;13:56-68.

15. Twomey C, O'Reilly G, Byrne M. Effectiveness of cognitive behavioural therapy for anxiety and depression in primary care: a meta-analysis. Fam Pract 2015;32:3-15

16. Butler M, Kane RL, McAlpine D, et al. Integration of mental health/ substance abuse and primary care. No. 173 (Prepared by the Minnesota Evidence-based Practice Center under contract no. 290-02-0009). AHRQ Publication no. 09-E003. Rockville, MD: Agency for Healthcare Research and Quality, 2008.

17. Durbin A, Durbin J, Hensel JM, et al. Barriers and enablers to integrating mental health into primary care: a policy analysis. $J$ Behav Health Serv Res 2016;43:127-39. Epub ahead of print:1-12.

18. Starkes JM, Poulin CC, Kisely SR. Unmet need for the treatment of depression in Atlantic Canada. Can J Psychiatry 2005;50:580-90.

19. Patten SB, Beck C. Major depression and mental health care utilization in Canada: 1994 to 2000. Can J Psychiatry 2004;49:303-9.

20. Kurdyak PA, Gnam WH. Medication management of depression: the impact of comorbid chronic medical conditions. J Psychosom Res 2004:57:565-71.

21. Vasiliadis HM, Lesage A, Adair C, et al. Service use for mental health reasons: cross-provincial differences in rates, determinants, and equity of access. Can J Psychiatry 2005;50:614-19.

22. Vasiliadis HM, Lesage A, Adair C, et al. Do Canada and the United States differ in prevalence of depression and utilization of services? Psychiatr Serv 2007;58:63-71. 
23. Lesage A, Vasiliadis HM, Gagné MA, et al. Prevalence of mental illnesses and related service utilization in Canada: an analysis of the Canadian Community Health Survey. Mississauga, ON: Canadian Collaborative Mental Health Initiatve, 2006.

24. Dezetter A, Duhoux A, Menear M, et al. Reasons and determinants for perceiving unmet needs for mental health in primary care in Quebec. Can J Psychiatry 2015;60:284-93.

25. Muggah E, Hogg W, Dahrouge S, et al. Patient-reported access to primary care in Ontario: effect of organizational characteristics. Can Fam Physician 2014;60:e24-31.

26. Mitchell AJ, Vaze A, Rao S. Clinical diagnosis of depression in primary care: a meta-analysis. Lancet 2009;374:609-19.

27. Fernández A, Rubio-Valera M, Bellon JA, et al. Recognition of anxiety disorders by the general practitioner: results from the DASMAP study. Gen Hosp Psychiatry 2012;34:227-33.

28. Vermani M, Marcus M, Katzman MA. Rates of detection of mood and anxiety disorders in primary care: a descriptive, cross-sectional study. Prim Care Companion CNS Disord 2011:13

29. Dell'Osso B, Altamura AC. Prevalent burdensome mental disorders remain untreated for years: manifesto for early diagnosis and treatment. Acad Psychiatry 2015;39:231-2.

30. Altamura AC, Camuri G, Dell'Osso B. Duration of untreated illness and duration of illness in anxiety disorders: assessment and influence on outcome. Mod Trends Pharmacopsychiatri 2013;29:111-18.

31. Duhoux A, Fournier L, Menear M. Quality indicators for depression treatment in primary care: a systematic literature review. Current Psychiatry Reviews 2011;7:104-37.

32. Roberge P, Fournier L, Menear M, et al. Access to psychotherapy for primary care patients with anxiety disorders. Canadian Psychology 2014;55:60-7.

33. Weisberg RB, Beard C, Moitra E, et al. Adequacy of treatment received by primary care patients with anxiety disorders. Depress Anxiety 2014;31:443-50.

34. Parikh SV, Lesage AD, Kennedy SH, et al. Depression in Ontario: under-treatment and factors related to antidepressant use. $J$ Affect Disord 1999;52:67-76.

35. Hutchison B, Levesque JF, Strumpf E, et al. Primary health care in Canada: systems in motion. Milbank Q 2011;89:256-88.

36. Hutchison B, Glazier R. Ontario's primary care reforms have transformed the local care landscape, but a plan is needed for ongoing improvement. Health Aff (Millwood) 2013;32:695-703.

37. Ministry of Health and Long-Term Care. Family Health Teams. Retrieved September 9, 2016. http://www.health.gov.on.ca/en/pro/ programs/fht/

38. Glazier R, Zagorski BM, Rayner J. Comparison of primary care models in Ontario by demographics, case mix and emergency department use, 2008/09 to 2009/10. ICES investigative report. Toronto, ON: Institute for Clinical Evaluative Services, 2012.

39. Glazier RH, Kopp A, Schultz SE, et al. All the right intentions but few of the desired results: lessons on access to primary care from Ontario's patient enrolment models. Healthc Q 2012;15:17-21.

40. The College of Family Physicians of Canada. A vision for Canada: family practice-The patient's medical home. The College of Family Physicians of Canada, Toronto, ON: 2011

41. Ministry of Health and Long-Term Care. Family Health Teams-Advancing primary care. Guide to interdisciplinary team roles and responsibilities. Toronto, ON: MOHLTC, 2005.

42. Ministry of Health and Long-Term Care. Open minds, healthy minds: Ontario's comprehensive mental health and addictions strategy. Toronto, ON: MOHLTC, 2011.

43. Jones W, Menear M, Petermann L, et al. An environmental scan of Canadian provincial and territorial initiatives directed toward improving primary mental health care delivery. Ottawa, ON: Mental Health Commission of Canada, 2012.

44. Gagné MA. What is collaborative mental health care? An introduction to the collaborative mental health care framework. Mississauga, ON: Canadian Collaborative Mental Health Initiative, 2005.

45. Katon W, Unützer J, Wells $\mathrm{K}$, et al. Collaborative depression care: history, evolution and ways to enhance dissemination and sustainability. Gen Hosp Psychiatry 2010;32:456-64.

46. Archer J, Bower P, Gilbody S, et al. Collaborative care for depression and anxiety problems. Cochrane Database Syst Rev 2012;10:CD006525.

47. Katon WJ, Lin EH, Von Korff M, et al. Collaborative care for patients with depression and chronic illnesses. N Engl J Med 2010;363:2611-20.

48. Huang $\mathrm{Y}$, Wei $\mathrm{X}, \mathrm{Wu} \mathrm{T}$, et al. Collaborative care for patients with depression and diabetes mellitus: a systematic review and meta-analysis. BMC Psychiatry 2013;13:260.
49. Mulvale G, Danner U, Pasic D. Advancing community-based collaborative mental health care through interdisciplinary family health teams in Ontario. Can J Commun Ment Health 2008;27:55-73.

50. Sherman J, Pong R, Swenson R, et al. Mental health services in smaller Northern Ontario Communities: a survey of Family Health Teams. Sudbury, ON: Centre for Rural and Northern Health Research, 2010.

51. Conference Board of Canada. Final report: an external evaluation of the Family Health Team (FHT) initiative. Ottawa, ON: The Conference Board of Canada, 2014.

52. Yip WC, Hsiao W, Meng Q, et al. Realignment of incentives for health-care providers in China. Lancet 2010;375:1120-30.

53. Scott A, Connelly LB. Financial incentives and the health workforce. Aust Health Rev 2011:35:273-7.

54. Wright CJ. Physician remuneration methods: the need for change and flexibility. CMAJ 1996;154:678-80.

55. Alvanzo AH, Cohen G, Nettleman M. Changing physician behavior: half-empty or half-full? Clinical Governance 2003;8:69-78.

56. Howell S. Investigating the interplay between policy change and incentives in sport and recreation. Purdue University, 2011.

57. McDonald R, Roland M. Pay for performance in primary care in England and California: comparison of unintended consequences. Ann Fam Med 2009;7:121-7.

58. Albanese M, Mejicano G, Xakellis G, et al. Physician practice change I: a critical review and description of an Integrated Systems Model. Acad Med 2009;84:1043-55.

59. Margolius D, Bodenheimer T. Transforming primary care: from past practice to the practice of the future. Health Aff (Millwood) 2010;29:779-84.

60. Hillman AL, Ripley K, Goldfarb N, et al. The use of physician financial incentives and feedback to improve pediatric preventive care in Medicaid managed care. Pediatrics 1999;104Pt 1):931-5.

61. Flodgren G, Eccles MP, Shepperd S, et al. An overview of reviews evaluating the effectiveness of financial incentives in changing healthcare professional behaviours and patient outcomes. Cochrane Database Syst Rev 2011:(7):CD009255.

62. Van Herck P, De Smedt D, Annemans L, et al. Systematic review: effects, design choices, and context of pay-for-performance in health care. BMC Health Serv Res 2010;10:247.

63. Eijkenaar F. Pay for performance in health care: an international overview of initiatives. Med Care Res Rev 2012;69:251-76.

64. Scott A, Sivey P, Ait Ouakrim D, et al. The effect of financial incentives on the quality of health care provided by primary care physicians. Cochrane Database Syst Rev 2011;(9):CD008451.

65. Gillam SJ, Siriwardena AN, Steel N. Pay-for-performance in the United Kingdom: impact of the quality and outcomes framework: a systematic review. Ann Fam Med 2012;10:461-8.

66. Langdown C, Peckham S. The use of financial incentives to help improve health outcomes: is the quality and outcomes framework fit for purpose? A systematic review. J Public Health 2014;36:251-8.

67. Houle SK, McAlister FA, Jackevicius CA, et al. Does performance-based remuneration for individual health care practitioners affect patient care?: a systematic review. Ann Intern Med 2012;157:889-99.

68. Eijkenaar F, Emmert M, Scheppach M, et al. Effects of pay for performance in health care: a systematic review of systematic reviews. Health Policy 2013;110:115-30.

69. Custers T, Hurley J, Klazinga NS, et al. Selecting effective incentive structures in health care: a decision framework to support health care purchasers in finding the right incentives to drive performance. BMC Health Serv Res 2008;8:66.

70. Greenberg D, Peiser JG, Peterburg Y, et al. Reimbursement policies, incentives and disincentives to perform laparoscopic surgery in Israel. Health Policy 2001;56:49-63.

71. McDonald R, White J, Marmor TR. Paying for performance in primary medical care: learning about and learning from "success" and "failure" in England and California. J Health Polit Policy Law 2009:34:747-76.

72. Merrell K, Berenson RA. Structuring payment for medical homes. Health Aff (Millwood) 2010;29:852-8.

73. Deber R, Hollander MJ, Jacobs P. Models of funding and reimbursement in health care: a conceptual framework. Canadian Public Administration 2008:51:381-405.

74. Ashcroft R, Silveira J, McKenzie K. Physicians' perspectives of the incentives and disincentives influencing care for depression and anxiety in Ontario Family Health Teams. Healthc Policy 2016:12:84-96.

75. Steele LS, Durbin A, Sibley LM, et al. Inclusion of persons with mental illness in patient-centred medical homes: cross-sectional findings from Ontario, Canada. Open Med 2013;7:e9-20. 
76. Goldberg RJ. Financial incentives influencing the integration of mental health care and primary care. Psychiatr Serv 1999;50:1071-5.

77. Libby AM, Riggs PD. Integrated substance use and mental health treatment for adolescents: aligning organizational and financial incentives. J Child Adolesc Psychopharmacol 2005;15:826-34.

78. Petterson SM, Phillips RL, Jr., Bazemore AW, et al. Why there must be room for mental health in the medical home. Am Fam Physician 2008;77:757.

79. Glasziou PP, Buchan $\mathrm{H}$, Del Mar $\mathrm{C}$, et al. When financial incentives do more good than harm: a checklist. BMJ 2012;345:e5047.

80. Frølich A, Talavera JA, Broadhead P, et al. A behavioral model of clinician responses to incentives to improve quality. Health Policy 2007;80:179-93.

81. Chaim G, Skinner W, Henderson J. Screening and assessing substance use and mental health concerns. In: Khenti A, Sapag J, Mohamoud S, et al, eds. Collaborative mental health. an advanced manual for primary care professionals. Toronto, ON: $\mathrm{CAMH}, 2012: 75-83$.

82. Gunn J, Dowrick C, Lionis C. Depression in primary care mental health. In: Ivbijario G, edr. Companion to primary care mental health. London, UK: Radcliffe, 2012:318-35.

83. Spitzer RL, Kroenke K, Linzer M, et al. Health-related quality of life in primary care patients with mental disorders. Results from the PRIME-MD 1000 Study. JAMA 1995;274:1511-17.

84. DeGruy F. Mental health care in the primary care setting. In: Committee on the Future of Primary Care loM, ed. Primary care:
America's health in a New Era. Washington DC: National Academy Press, 1996:285-311.

85. Dowell T, Morris C, Dodd T, et al. Psychological interventions in primary care mental health. In: Ivbijario G, ed. Companion to primary care mental health. London, UK: Radcliffe, 2012:241-64.

86. Rosser WW, Colwill JM, Kasperski J, et al. Progress of Ontario's Family Health Team model: a patient-centered medical home. Ann Fam Med 2011;9:165-71.

87. Charmaz K. Constructing Grounded Theory (2nd ed.). Thousand Oaks, CA: Sage, 2014

88. Thurston WE, Coupal S, Jones CA, et al. Discordant indigenous and provider frames explain challenges in improving access to arthritis care: a qualitative study using constructivist grounded theory. Int $J$ Equity Health 2014;13:46

89. Mian O, Koren I, Rukholm E. Nurse practitioners in Ontario primary healthcare: referral patterns and collaboration with other healthcare professionals. J Interprof Care 2012;26:232-9.

90. Benzer JK, Beehler S, Miller C, et al. Grounded theory of barriers and facilitators to mandated implementation of mental health care in the primary care setting. Depress Res Treat 2012;2012:597157.

91. Webster F, Perruccio AV, Jenkinson R, et al. Where is the patient in models of patient-centred care: a grounded theory study of total joint replacement patients. BMC Health Serv Res 2013;13:531.

92. Corbin J, Straus A. Basics of Qualitative Research (3rd edition). Thousand Oaks, CA: Sage Publications, 2008.

93. Creswell J. Qualitative inquiry \& research design. choosing among five approaches. Thousand Oaks, CA: Sage Publications, 2007. 